\title{
Determination of healthy lifestyle behaviors of high school students
}

\section{Lise öğrencilerinin sağlıklı yaşam biçimi davranışlarının belirlenmesi $^{1}$}

\author{
Mehtap Metin Karaaslan ${ }^{2}$ \\ Ayda Çelebioğlu ${ }^{3}$
}

Özet

$\mathrm{Bu}$ araştırma, lise öğrencilerinin sağlıklı yaşam biçimi davranışlarının belirlenmesi amacıyla tanımlayıcı olarak gerçekleştirilmiştir. Rize il merkezinde bulunan okullar gruplandırılmıstır(n: 9926). Evrende birey say1s1 bilinen örneklem genişliği formülüne göre örneklem sayıs1 370 olarak belirlenmiş, her gruptaki birer liseden basit rastgele örneklem yöntemiyle toplam 449 gönüllü öğrenci ile çalışma tamamlanmıştır. Verilerin toplanmasında, araştırmacı tarafindan oluşturulan kişisel bilgi formu ve sağlıklı yaşam biçimi davranışları ölçeği II kullanılmıştır. Veriler bilgisayar ortaminda yüzdelik, ANOVA ve t testi kullanılarak değerlendirilmiştir.Öğrencilerin sağlıklı yaşam biçimi davranışları ölçeği puan ortalamasinin 128.06 \pm 20.19 ile orta düzeyde olduğu belirlenmiştir. Kız öğrencilerin sağllk sorumluluğu ve kişilerarası ilişkiler puan ortalaması erkek öğrencilerin puan ortalamasından yüksek bulunmuştur $(\mathrm{p}<0.05)$. Erkek öğrencilerin fiziksel aktivite puan ortalamas1, kız öğrencilerin puan ortalamasından yüksek bulunmuştur $(\mathrm{p}<0.05)$. Öğrencilerin yaş1 ve sınıf ile 'kişilerarası ilişkiler' ve toplam puan arasında pozitif yönde anlamlı ilişki saptanmıştır $(p<0.05)$.Adölesan döneminde olumlu sağlık davranışlarının kazanılması bireyin ileriki yaşamında sağlıklı davranışlar gerçekleştirmesi açısından önem taşımaktadır. $\mathrm{Bu}$ çalışma

\footnotetext{
1 Bu çalışma 16-18 Mart 2017 İzmir, 1. Internatıonal Congress On Nursıng kongresinde sözlü bildiri olarak sunulmuştur.

2 Teaching Assistant Recep Tayyip Erdogan University, m.metinkaraaslan@gmail.com

3 Professor Doctor, Mersin University, İçel Health High School, Aydaç@mersin.edu.tr
} 
Metin Karaaslan, M., \& Çelebioğlu, A. (2018). Lise öğrencilerinin sağlıklı yașam biçimi davranışlarının belirlenmesi. Journal of Human Sciences, 15(2), 1355-1361. doi:10.14687/ihs.v15i2.4895

important to perform healthy behaviors in the future life of the individual. As a result of this study, it is suggested that education programs should be established to protect and improve the health of the students. Also, education should develop the self-efficacy of the students. Moreover, it should be conducted according to the low-scored areas and schools.

Keywords: Healthy lifestyle behaviors; Health promotion; High school students.

(Extended English summary is at the end of this document) sonucunda öğrencilerin sağlıklarını korumak ve geliştirmek için eğitim programları oluşturulması ve eğitimin özellikle öz- etkililiği geliştirici olması ve daha çok düşük puan alınan alanlara ve okullara göre yapılması önerilmektedir.

Anahtar Kelimeler: Sağlıklı yaşam biçimi davranışları; Sağlığın geliştirilmesi; Lise öğrencileri.

\section{Giriş}

Sağlığın geliştirilmesi, kişinin sağllğı üzerindeki denetimini arttırma gücünü başarma süreci ve sağlı̆̆ını sürekli geliştirmesi olarak tanımlanmaktadır (World Health Organization, [Who], 1986). Bireylerin sağlıklı olabilmeleri için sağlıklı yaşam biçimini hayat tarzı olarak benimsemeleri ve davranışa dönüştürmeleri gerekmektedir. Sağlıklı yaşam biçimi davranışları yeterli ve dengeli beslenme, verimli uyku, düzenli egzersiz yapma, güvenli cinsel davranışlar, sigara içme, alkol ve madde kullanma gibi riskli davranışları benimsememe olarak sayılabilir (Çapık ve Gözüm, 2014; Sağllğın Geliștirilmesi Eğitimi Rehberi 2011). Adölesan dönemi fiziksel ve ruhsal değişimlerin yoğun olarak yaşandığı bir evredir. Sağlıklı yaşam biçimi davranışları çoğunlukla ergenlik dönemde kazanılır ve bu dönemde kazanılan olumlu ya da olumsuz davranış kişiyi hayatı boyunca etkilemektedir (Geçkil ve Yıldız, 2006a). Bu amaçla, geleceğimizin temelini oluşturan ve riskli davranışlara kayma olasılığı olan adölesanların sağlıklı yaşam biçimi davranışlarını belirlemek ve geliştirmek üzere çalışma planlanmıştır.

\section{Gereç Yöntem}

$\mathrm{Bu}$ araştırma lisede öğrenim gören öğrencilerin davranışlarının, sağlıklı yaşam biçimi tarzına uygun olup olmadığını tespit etmek amacıyla tanımlayıcı olarak gerçekleştirilmiştir. 2015-2016 eğitim öğretim yılında Rize merkezde bulunan orta öğretim kurumları araştırmanın evrenini oluşturmuştur (N: 9926). Evrende birey sayısı bilinen örneklem genişliği formülüne göre örneklem sayıs1 370 olarak belirlenmiş, Rize il merkezindeki okullar türlerine göre gruplandırılmış ve her gruptaki birer liseden basit rastgele örneklem yöntemiyle toplam 449 gönüllü öğrenci ile çalışma tamamlanmıştır. Verilerin toplanmasında literatür taraması sonucu cinsiyet, yaş, sınıf ve okul olmak üzere toplam 4 maddeden oluşan soru formu ile Sağlıklı Yaşam Biçimi Davranışları Ölçeği II (SYBDÖ II) kullanılmıştır.

1987 yllinda Walker tarafindan geliştirilen SYBDÖ II, 1996 yllında altı faktör ve 52 madde olarak revize edilmiştir. Ölçeğin alt faktörleri; 'Manevi Gelişim, Kişilerarası Ilişkiler, Beslenme, Fiziksel Aktivite, Sağlık Sorumluluğu ve Stres Yönetimi'dir. Tüm ölçekten alınan en az puan 52, en fazla puan 208 olup, Bahar ve arkadaşları (2008) tarafından türkçe geçerlilik güvenilirliği yapılmıştır. Cronbach alpha değeri toplam ölçek için .94 olup bu çalışmada toplam ölçek için cronbach Alpha değeri 0.90 bulunmuştur. 
Metin Karaaslan, M., \& Çelebioğlu, A. (2018). Lise öğrencilerinin sağlıklı yașam biçimi davranışlarının belirlenmesi. Journal of Human Sciences, 15(2), 1355-1361. doi:10.14687/ihs.v15i2.4895

Veriler bilgisayarda SPSS 22.0 sürümünde frekans, yüzde, ANOVA ve t testleri kullanilarak değerlendirilmiştir. Çalışma rize il merkezindeki orta okullarda yürütüldüğü için sadece bu bölge ile sınırlıdır, genellenemez. Araştırma için Recep Tayyip Erdoğan Üniversitesi etik kurulundan ve Rize İl Milli Eğitim Müdürlüğünden yazılı izin alınmıştır. Öğrencilere araştırmanın amacı ifade edildikten sonra araştırmaya katılmayı onaylayan öğrenciler çalışmaya alınmıştır.

\section{Bulgular}

Öğrencilerin \%65.7’si kız, \%29.0’1 16 yaşındadır. \%29.8’i birinci sınıf ve \%42.8'i Mesleki ve Teknik Anadolu lisesi öğrencisidir (Tablo1).

Öğrencilerin sağlık sorumluluğu puan ortalamasının $17.47 \pm 5.05$ ile en düşük, manevi gelişim puan ortalamasının $26.23 \pm 4.87$ ile en yüksek olduğu bulunmuştur. Öğrencilerin toplam puan ortalamasının 128.06 \pm 20.19 ile orta düzeyde olduğu belirlenmiştir (Tablo2).

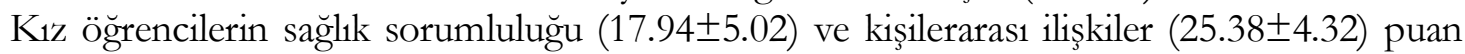
ortalaması (125.21 \pm 19.81$)$ erkek öğrencilerin sağllk sorumluluğu $(16.56 \pm 5.00)$ ve kişilerarası ilişkiler (24.42 \pm 4.30$)$ puan ortalamasindan $(124.78 \pm 20.96)$ yüksek bulunmuştur ve bu fark istatistiksel

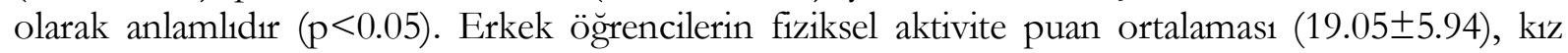

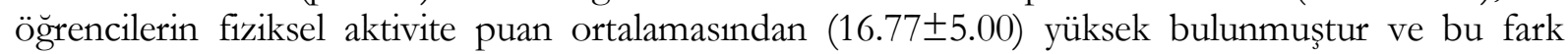
anlamlıdır $(p<0.05)$. 4. sınıf öğrencilerin sağlık sorumluluğu $(18.27 \pm 5.00)$, beslenme $(20.05 \pm 3.99)$ ve toplam (128.39 \pm 19.44$)$ puan ortalaması diğer öğrencilerin sağlık sorumluluğu, beslenme ve toplam puan ortalamalarından $(16.56 \pm 5.00)$ yüksektir ve gruplar arasındaki fark anlamlıdır $(\mathrm{p}<0.05)$. 3. sınıf

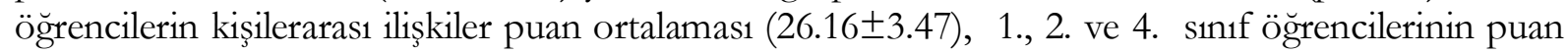
ortalamasından yüksektir ve bu fark anlamlı istatistiksel olarak bulunmuştur $(\mathrm{p}<0.05)$. Fen lisesi

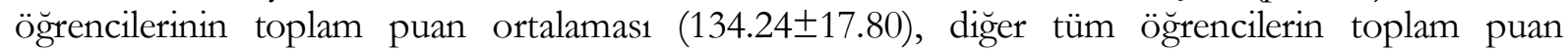

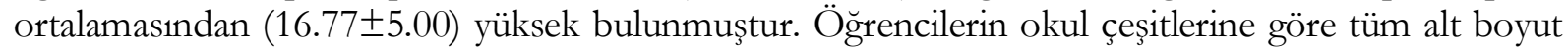
ve toplam puan ortalamaları açısından gruplar arasındaki fark anlamlıdır $(p<0.05)$ (Tablo3). Yaş ve sınıf ile 'kişilerarası ilişkiler' ve toplam puan arasındaki ilişki pozitif yönde anlamlı olarak bulunmuştur $(\mathrm{p}<0.05)$ (Tablo4).

\section{Tablolar}

Tablo 1. Öğrencilerin Demografik Özelliklerine Göre Dağılımı

\begin{tabular}{lll}
\hline Özellikler & $\mathrm{S}$ & $\%$ \\
\hline Cinsiyet & 295 & 65.7 \\
\hline Kız & 154 & 34.3 \\
\hline Yrkek & & 26.3 \\
\hline Yaş & 118 & 29.0 \\
15 & 130 & 24.5 \\
17 & 110 & 20.2 \\
18 & 91 & \\
\hline Yaş Ortalama & & $16.38 \pm 1.15$ \\
\hline Sinif & 449 & 29.8 \\
\hline 1 & & 25.2 \\
2 & 134 & 19.8 \\
3 & 113 & 25.2 \\
4 & 89 & 42.8 \\
\hline Okul & 113 & 24.7 \\
\hline Mesleki ve Teknik Anadolu Lisesi & & 7.3 \\
Anadolu Lisesi & 192 & 10.9 \\
Fen Lisesi & 111 & 14.3 \\
Spor, Güzel Sanatlar ve Sosyal Bilimler Lisesi & 33 & \\
İmam Hatip Lisesi & 49 & 64 \\
\hline
\end{tabular}


Metin Karaaslan, M., \& Çelebioğlu, A. (2018). Lise öğrencilerinin sağlıklı yașam biçimi davranışlarının belirlenmesi. Journal of Human Sciences, 15(2), 1355-1361. doi:10.14687/ihs.v15i2.4895

Tablo 2. Ögrencilerin SYBD Alt Boyut ve Toplam Puan Ortalamaları

\begin{tabular}{llllll}
\hline & $\mathrm{S}$ & Minimum & Maximum & $\mathrm{X}$ & SS \\
\hline Sağlık Sorumluluğu & 449 & 2.00 & 32.00 & 17.47 & 5.05 \\
Fiziksel Aktivite & 449 & 8.00 & 32.00 & 17.55 & 5.44 \\
Beslenme & 449 & 9.00 & 33.00 & 19.61 & 3.88 \\
Manevi Gelişim & 449 & 13.00 & 36.00 & 26.23 & 4.87 \\
Kişilerarası İlişkiler & 449 & 13.00 & 36.00 & 25.05 & 4.33 \\
Stres Yönetimi & 449 & 9.00 & 30.00 & 19.09 & 3.92 \\
SYBD Toplam Puan & 449 & 74.00 & 184.00 & 128.06 & 20.19 \\
\hline
\end{tabular}

Tablo 3. Sağlıklı Yaşam Biçimi Davranışlarının Öğrencilerin Demografik Özeliklerine Göre Karșılaștırılması

\begin{tabular}{|c|c|c|c|c|c|c|c|}
\hline \multicolumn{8}{|c|}{ SYBD PUAN ORTALAMALARI } \\
\hline Özellikler & SS & FA & Beslenme & MG & KAİ & SY & Toplam \\
\hline \multicolumn{8}{|l|}{ Cinsiyet } \\
\hline $\mathrm{K}_{12}$ & $17.94 \pm 5.02$ & $16.77 \pm 5.00$ & $19.44 \pm 3.93$ & $26.34 \pm 4.95$ & $25.38 \pm 4.32$ & $19.24 \pm 3.94$ & $125.21 \pm 19.81$ \\
\hline Erkek & $16.56 \pm 5.00$ & $19.05 \pm 5.94$ & $19.92 \pm 3.77$ & $26.02 \pm 4.72$ & $24.42 \pm 4.30$ & $18.79 \pm 3.86$ & $124.78 \pm 20.96$ \\
\hline $\mathrm{t}$ & 2.77 & -4.06 & -1.24 & 0.65 & 2.24 & 1.16 & 0.21 \\
\hline $\mathrm{p}$ & 0.00 & 0.00 & 0.21 & 0.51 & 0.02 & 0.24 & 0.83 \\
\hline \multicolumn{8}{|l|}{ Yaş } \\
\hline Yaş Ort. & $17.47 \pm 5.05$ & $17.55 \pm 5.44$ & $19.61 \pm 3.88$ & $26.23 \pm 4.87$ & $25.05 \pm 4.33$ & $19.09 \pm 3.92$ & $125.06 \pm 20.19$ \\
\hline $\mathrm{F}$ & 1.22 & 1.29 & 2.28 & 1.03 & 2.02 & 1.84 & 1.94 \\
\hline $\mathrm{p}$ & 0.29 & 0.26 & 0.04 & 0.40 & 0.07 & 0.10 & 0.08 \\
\hline \multicolumn{8}{|l|}{ Sinif } \\
\hline 1 & $17.52 \pm 5.13$ & $17.84 \pm 5.27$ & $19.73 \pm 3.93$ & $26.04 \pm 5.00$ & $24.66 \pm 4.57$ & $19.00 \pm 4.04$ & $124.80 \pm 21.29$ \\
\hline 2 & $16.28 \pm 5.28$ & $16.43 \pm 5.90$ & $18.75 \pm 3.76$ & $25.60 \pm 5.23$ & $24.14 \pm 4.71$ & $18.59 \pm 4.17$ & $119.99 \pm 21.19$ \\
\hline 3 & $17.89 \pm 4.48$ & $17.92 \pm 5.37$ & $19.96 \pm 3.70$ & $26.58 \pm 4.20$ & $26.16 \pm 3.47$ & $19.13 \pm 3.35$ & $127.67 \pm 16.82$ \\
\hline 4 & $18.27 \pm 5.00$ & $18.04 \pm 5.13$ & $20.05 \pm 3.99$ & $26.81 \pm 4.81$ & $25.54 \pm 4.04$ & $19.66 \pm 3.90$ & $128.39 \pm 19.44$ \\
\hline $\mathrm{F}$ & 3.29 & 2.17 & 2.65 & 1.39 & 4.58 & 1.44 & 3.98 \\
\hline $\mathrm{p}$ & 0.02 & 0.09 & 0.04 & 0.24 & 0.00 & 0.23 & 0.00 \\
\hline \multicolumn{8}{|l|}{ Okul } \\
\hline MTAL & $16.52 \pm 4.83$ & $16.73 \pm 5.10$ & $18.82 \pm 3.88$ & $25.30 \pm 4.80$ & $24.00 \pm 4.55$ & $18.34 \pm 3.79$ & $119.83 \pm 19.89$ \\
\hline Anadolu Lisesi & $17.62 \pm 5.29$ & $18.76 \pm 5.84$ & $19.96 \pm 3.75$ & $25.89 \pm 5.15$ & $24.95 \pm 4.12$ & $19.23 \pm 4.02$ & $126.43 \pm 20.75$ \\
\hline Fen Lisesi & $19.33 \pm 5.16$ & $17.90 \pm 4.99$ & $21.06 \pm 4.19$ & $28.36 \pm 4.35$ & $27.00 \pm 3.52$ & $20.57 \pm 4.12$ & $134.24 \pm 17.80$ \\
\hline SGSSBL & $19.02 \pm 5.61$ & $20.18 \pm 5.79$ & $20.06 \pm 4.01$ & $26.89 \pm 4.81$ & $26.32 \pm 3.99$ & $20.38 \pm 4.01$ & $133.18 \pm 22.02$ \\
\hline İHL & $17.93 \pm 4.24$ & $15.70 \pm 4.50$ & $20.04 \pm 3.43$ & $28.01 \pm 4.04$ & $26.40 \pm 3.76$ & $19.32 \pm 3.50$ & $127.43 \pm 15.15$ \\
\hline $\mathrm{F}$ & 4.24 & 7.61 & 4.13 & 6.09 & 7.54 & 4.49 & 7.68 \\
\hline $\mathrm{p}$ & 0.00 & 0.00 & 0.00 & 0.00 & 0.00 & 0.00 & 0.00 \\
\hline
\end{tabular}

*MTAL: Mesleki ve Teknik Anadolu Lisesi, SGSSBL: Spor, Güzel Sanatlar ve Sosyal Bilimler Lisesi, İHL: İmam Hatip Lisesi

Tablo 4. Öğrencilerin Demografik Özellikleri İle SYBD Puan Ortalamaları Arasındaki İlişki

\begin{tabular}{lllllllll}
\hline & & SS & FA & Beslenme & MG & KAI & SY & Toplam \\
\multirow{2}{*}{ Yaş } & $\mathrm{r}$ & 0.08 & 0.06 & 0.05 & 0.08 & 0.09 & 0.08 & 0.10 \\
& $\mathrm{p}$ & 0.06 & 0.14 & 0.27 & 0.08 & $\mathbf{0 . 0 4}$ & 0.06 & 0.02 \\
\hline \multirow{2}{*}{ Sinıf } & $\mathrm{r}$ & 0.08 & 0.04 & 0.05 & 0.07 & 0.11 & 0.07 & 0.10 \\
& $\mathrm{p}$ & 0.07 & 0.35 & 0.21 & 0.12 & $\mathbf{0 . 0 1}$ & 0.11 & 0.03 \\
\hline
\end{tabular}

\section{Tartışma}

Öğrencilerin SYBD toplam puan ortalamasının genel anlamda orta düzeyde olduğu belirlenmiștir. Literatürde çeșitli ölçeklerle sağlıklı yaşam biçimi davranışlarını ölçen benzer sonuçlara rastlanmaktadır (Geçkil ve Yıldız, 2006a; Dil, Şentürk ve Girgin, 2015; Dağdeviren ve Şimşek, 2013; Geçkil ve Yıldız, 2006b; Karadamar, Yiğit ve Sungur, 2014; Özakgül, Aşt1, Ataç ve Mercan 2016; Bebiş, Akpunar, Özdemir ve Kılıç, 2015; Musavian, Pasha, Rahebi, Roushan ve Ghanbari, 2014). Bu durum öğrencilerin yeterli düzeyde sağlık eğitimi almadığını ya da alınan eğitimi davranışlarına yansıtamadığını düşündürmektedir. 
Metin Karaaslan, M., \& Çelebioğlu, A. (2018). Lise öğrencilerinin sağlıklı yaşam biçimi davranışlarının belirlenmesi. Journal of Human Sciences, 15(2), 1355-1361. doi:10.14687/ihs.v15i2.4895

Öğrencilerin ölçek alt boyutlarından aldıkları puanlara bakıldığında; en fazla puanın manevi gelişim alt boyutundan, en az puanın ise sağlık sorumluluğu alt boyutundan alındığ1 görülmüștür. Bu çalışmada elde edilen bulgulara parelel olarak Özakgül, ve arkadaşlarinin (10) yaptığı çalışmada da manevi gelişim alt boyutu yüksek bulunmuştur. Ayrıca SYBDÖ II'de manevi gelişim boyutu SYBDÖ ve adölesan sağlı̆̆1 geliştirme ölçeğinde kendini gerçekleştirme alt boyutu olarak adlandırılmakta ve çalışmamızı desteklemektedir (Geçkil ve Yıldız, 2006a; Dil vd, 2015; Dağdeviren ve Şimşek, 2013; Geçkil ve Yıldız, 2006b; Karadamar vd, 2014; Bebiş vd, 2015; Musavian vd, 2014).

Cinsiyete göre ölçek alt boyutları incelendiğinde, kı öğrencilerin sağlık sorumluluğu ve kişilerarası ilişkiler puan ortalaması erkek öğrencilerin puan ortalamalarından yüksek ve fark anlamlı bulunmuş̧tur $(\mathrm{p}<0.05)$. Bu sonuç Bebiş ve arkadaşlarının (2015) çalışması ile aynıdır.

Erkek öğrencilerin fiziksel aktivite puan ortalaması ise kız öğrencilerin puan ortalamasından yüksektir ve fark anlamlı bulunmuştur $(\mathrm{p}<0.05)$. Literatürde bu sonucu destekleyen çalışmalara rastlanmıştır (Geçkil ve Yıldız, 2006b; Karadamar vd, 2014; Yıldız ve Yıldırım, 2012; Ardıç ve Esin, 2016; Costa-Tutusaus ve Guerra- Balic, 2016). Bu durum erkeklerin toplumsal cinsiyet algisindan etkilendiklerini ve daha aktif bir yaşam sürdürdüklerini ve sporun yaşamlarının önemli bir parçası olduğunu düşündürmektedir.

Fen lisesi öğrencilerinin toplam puan ortalaması, diğer tüm öğrencilerin toplam puan ortalamasından yüksek bulunmuştur. Öğrencilerin okul çeşitlerine göre tüm alt boyut ve toplam puan ortalamaları açısından fark anlamlı bulunmuştur $(p<0.05)$. Dağdeviren ve Şimşek (2013) Anadolu ve Fen liselerinde öğrenim gören öğrencilerin diğer okul türlerine göre fazla puan aldığını saptamıştır. Bu durum liselere yerleştirme sınavında daha yüksek puan öğrencilerin, alınan eğitimi davranışa dönüştürme becerilerinin daha iyi olduğunu düşündürmektedir.

Öğrencilerin sınıflarına göre toplam puan ortalaması açısından farkın istatistiksel olarak anlamlı olduğu, bu farkın lise 3. ile lise 4. Sınıf öğrencilerinden kaynaklandığı belirlenmiştir $(\mathrm{p}<0.05)$. Ayrıca yaş ve sınıf ile ölçek puan ortalamaları arasındaki ilişki incelendiğinde yaş ve sınıf yükseldikçe öğrencilerin puan ortalamalarının da arttığı belirlenmiştir. Bu durum yaşın sağlıklı davranış biçimlerini olumlu etkilediğini ve gençlerin kendi sorumluluklarını üstlenme adına gelişme gösterdiklerini düşündürmektedir. Ancak bu çalışmanın aksi yönünde sonuçlara da rastlanmaktadır. Bebiş ve ark. (2015) ile Musavian ve ark. (2014) lise 1 sınıf öğrencilerinin diğer öğrencilere göre daha olumlu davranışlar sergilediklerini bulmuşlardır. Bu farkın lise 2,3 ve 4. sınıf öğrencilerinin riskli adölesan döneminde olmasından kaynaklandığı düşünülmektedir.

\section{Sonuç}

Adölesan döneminde olumlu sağlık davranışlarının kazanılması bireyin ileriki yaşamında sağlıklı davranışlar gerçekleştirmesi açısından önem taşımaktadır. Çalışmaya katılan öğrencilerin sağlıklı yaşam biçimi davranışları orta düzeyde bulunmuştur. Bu çalışma sonucunda öğrencilerin sağllğını koruyucu ve geliştirici eğitim programları oluşturulması ve eğitimin özellikle öz- etkililiği geliştirici olması, daha çok düşük puan alınan alanlara ve okullara göre yapılması, eğitimlerin ders müfredatı dahilinde uygulanması önerilebilir.

\section{Kaynaklar}

Ardic A ve Esin MN. (2016). Factors associated with healthy lifestyle behaviors in a sample of Turkish adolescents: a school-based study. Journal Of Transcultural Nursing, 27(6),583 -592. DOI: $10.1177 / 1043659615587585$

Bahar Z, Beşer A, Gördes N, Ersin F, Kıssal A. (2008). Sağlıklı yaşam biçimi davranışları ölçeği II'nin geçerlilik ve güvenilirlik çalışması. Cumburiyet Üniversitesi Hemşirelik Yükesekokulu Dergisi,12(1):1-13.

Bebiş H, Akpunar D, Özdemir S, Kilıç S. (2015). Bir ortaöğretim okulundaki adölesanların sağlı̆̆ geliştirme davranışlarının incelenmesi. Gülhane T⿰р Dergisi, 57:129-135. 
Metin Karaaslan, M., \& Çelebioğlu, A. (2018). Lise öğrencilerinin sağlıklı yaşam biçimi davranışlarının belirlenmesi. Journal of Human Sciences, 15(2), 1355-1361. doi:10.14687/jhs.v15i2.4895

Costa-Tutusaus L, Guerra-Balic M. (2016). Relationship between healthy lifestyle and sociodemographic factors in adolescentsin catalonia: application of visa-teen questionnaire. Plos One, 11(9). Doi:10.1371/Journal. Pone.0163381.

Çapık C, Gözüm S. (2014). Sağlık davranışlarının geliştirilmesinde bir rehber: sağlık inanç modeli. Dokuz. Eylül Üniversitesi Hemsirelik Yülksekokulu Elektronik Dergisi, 7(3),230-237.

Dağdeviren Z, Şimşek Z. (2013). Şanlıurfa il merkezindeki lise öğrencilerinin sağlı̆̆1 geliştirme davranışlan ve ilişkili faktörler. TAF Preventive Medicine Bulletin, 12(2),135-142.

Dil S, Şentürk SG, Girgin BA. (2015). Çankırı ilinde ergenlerin benlik saygısı ve sağlıklı yaşam biçimi davranışlarının riskli davranışları ve sosyodemografik özelliklerle ilişkisi. Anadolu Psikiyatri Dergisi, 16,51-59.

Geçkil E, Yildız S. (2006). Adolescent health behaviors and problems. Hemșirelik Yülesekokulu Dergisi, 26-34.

Geçkil E, Yıldız S. (2006). Adölesanlara yönelik beslenme ve stresle baş etme eğitiminin sağlı̆ı geliştirmeye etkisi. Cumburiyet Üniversitesi Hemsirelik Yüksekokulu Dergisi,10(2),19-28.

Karadamar M, Yiğit R, ve Sungur MA. (2014). Ergenlerin sağlıklı yaşam biçimi davranışlarının değerlendirilmesi. Anadolu Hemşirelik ve Sağhlk Bilimleri Dergisi, 17(3),131-139.

Musavian AS, Pasha A, Rahebi SM, Roushan ZA, Ghanbari A. (2014). Health promoting behaviors among adolescents: a cross-sectional study. Nursing and Midwifery Studies, 3(1),1-7.

Özakgül AA, Aștı TA, Ataç M, Mercan K. (2016). Lise son sınıf öğrencileri sağllklı yaşam biçimi davranışlarına sahipler mi?. Florence Nightingale Hemssirelik Dergisi, 24(1),16-23.

Toplum Sağlığı Merkezi Çalıșanlarına Yönelik "Sağlığın Geliștirilmesi Eğitimi” Rehberi, T.C. Sağlık Bakanlı̆̆ı Temel Sağllk Hizmetleri Genel Müdürlüğü Sağlığın Teșviki ve Geliștirilmesi Daire Bașkanlığı, Ankara, 2011.

World Health Organization (Who), Ottawa Charter For Health Promotion, 1986. http://www.who.int/about/en/

Yildız I, Yildırım F. (2012). The relation between problematic internet use and healthy lifestyle behaviours in high school students. Advances in School Mental Health Promotion, 5(2),93-104.

\section{Extended English Summary}

Health promotion is defined as the process of enabling individuals to increase control over and to improve their health continuously (World Health Organization, [Who], 1986). It is necessary for individuals to adopt healthy life styles as a life style in order to be healthy. Adolescence period is a phase where physical and psychological changes happen intensely. Healthy life style behaviors are mainly acquired during this period and positive and negative behaviors acquired during adolescence period affect individuals during their whole life (Geçkil and Yildız, 2006a). Therefore, this study was planned to focus on and to develop healthy life styles behaviors of adolescents who are the basis of our future and are likely to tend to risky behaviors.

\section{Tools and Method}

This study was descriptively undertaken in order to explore whether or not behaviors of students of a high school were consistent with healthy life styles. High schools located in the city center of Rize Province during 2015-2016 academic year composed population of the study (N: 9926). The number of samples was determined to be 370 according to the sample width formula, which is known as the number of individuals in the phase. A total of 449 volunteer students were selected from a high school in each group by simple random sampling method and the study was completed. To gather the data; a survey form of four questions addressing participants' sex, age, academic grade and school type and Healthy LifeStyles Behaviors Scale II (HLSB II) were employed.

HLSB II, designed in 1987 by Walker, was classified into six subdimensions and 52 items in 1996. Subdimensions of the scale are spiritual development, interpersonal relationships, diet, physical activity, health responsibility and stress management. The lowest score that can be obtained from the scale is 52 while the highest score is 208 . Turkish validity and reliability tests of the scale were done by Bahar et al. (2008). Cronbach alpha value for the total scale was .94 and Cronbach alpha value for the current study was found to be 0.90 .

The data were processed using SPSS 22.0 and were analyzed through frequency, percentages, ANOVA and $t$ tests. Since the study was done at high schools located in the city center of Rize Province, it was limited only to these schools and cannot be generalized. The necessary official permissions were 
Metin Karaaslan, M., \& Çelebioğlu, A. (2018). Lise öğrencilerinin sağlıklı yaşam biçimi davranışlarının belirlenmesi. Journal of Human Sciences, 15(2), 1355-1361. doi:10.14687/jhs.v15i2.4895

obtained from the Ethical Committee of Recep Tayyip Erdoğan University and Directorate of National Education Ministry of Rize Province. Participants were informed of the nature of the study and those students who consented to participate were included in the study.

\section{Findings}

Students' total average score was found to be at moderate level (128.06 \pm 20.19$)$ (Table 2). Average scores of female students in health responsibility (17.94 \pm 5.02$)$, interpersonal relationships $(25.38 \pm 4.32)$ and total average score $(125.21 \pm 19.81)$ were found to be higher than those of male students thealth responsibility (16.56 \pm 5.00$)$, interpersonal relationships $(24.42 \pm 4.30)$ and total average score $(124.78 \pm 20.96)]$ and these differences were statistically significant $(\mathrm{p}<0.05)$. Average score of male students' physical activity $(19.05 \pm 5.94)$ were found to be higher than female students' physical activity average score $(16.77 \pm 5.00)$ and this difference was significant $(\mathrm{p}<0.05)$. $4^{\text {th }}$ year students' average scores of health responsibility $(18.27 \pm 5.00)$ and diet $(20.05 \pm 3.99)$ and average total score $(128.39 \pm 19.44)$ were higher than other students' average scores of health responsibility, diet and total score $(16.56 \pm 5.00)$ and these differences among the groups were statistically significant $(\mathrm{p}<0.05)$. Total average score of students who studied at science high schools (134.24 \pm 17.80$)$ was higher than that of other students $(16.77 \pm 5.00)$. According to school type; average scores of all subdimensions and total scores were significant among the groups $(\mathrm{p}<0.05)$ (Table 3$)$. Also; the correlation among age, academic grade and interpersonal relationships and total score was positively significant $(\mathrm{p}<0.05)$ (Table 4).

\section{Discussion}

It was identified that students' HLSB total average score was generally at a moderate level. Similar results of the studies that have measured healthy life styles behaviors through different scales can be seen in literature (Geçkil and Yıldız, 2006a; Dil, Şentürk and Girgin, 2015; Dağdeviren and Şimşek, 2013; Geçkil and Yıldız, 2006b; Karadamar, Yiğit and Sungur, 2014; Özakgül, Aş̧, Ataç and Mercan 2016; Bebiş, Akpunar, Özdemir and Kilıç, 2015; Musavian, Pasha, Rahebi, Roushan and Ghanbari, 2014). This indicates that students did not receive health education at a desired level or they were unable to turn this education into actions.

When students' subdimension scores were examined in terms of sex, it was identified that female students' average scores in health responsibility and interpersonal relationships were higher than those of male students' average scores and the difference was significant $(\mathrm{p}<0.05)$. This finding concurred with the finding of Bebiş et al. (2015).

On the other hand; male students' average score in physical activity was higher than that of female students' average score and the difference was significant $(\mathrm{p}<0.05)$. In literature, there are studies that argue the same finding (Geçkil and Yıldız, 2006b; Karadamar et al., 2014; Yıldız and Yıldırım, 2012; Ardıç and Esin, 2016; Costa-Tutusaus and Guerra- Balic, 2016). This made us conclude that males are affected by gender perception and lead a more active life and sports is a significant part of their lives. Total average score of students who studied at science high schools were found to be higher than total average score of other students. There was a significant difference in all average subdimension scores and average total score in terms of high school types $(\mathrm{p}<0.05)$. Dağdeviren and Şimşek (2013) suggested that students who studied at Anatolian and Science High schools demonstrated higher scores as compared to other students; which made us think that students who get a higher grade in placement examination for high schools were better at turning secondary school education into actions and behaviors. It was seen that students' total average score was statistically significant in terms of academic grades and the difference originated from $3^{\text {rd }}$ year students and $4^{\text {th }}$ year students $(\mathrm{p}<0.05)$. Meanwhile, when the correlation between age and academic grade and average scale scores were investigated, students' average scores went up as their academic class increased from a lower level to a higher level; which made us conclude that age affects healthy behavior styles positively and the youngsters tend to take their responsibilities. Yet, there are contradictory findings in the current study, too. The studies of Bebiş et al. (2015) and Musavian et al. (2014) explored that $1^{\text {st }}$ year high school students demonstrated more positive behaviors as compared to other students; which may have resulted from the fact that $2^{\text {nd }}, 3^{\text {rd }}$ and $4^{\text {th }}$ year students were in risky adolescence period.

\section{Result}

It is important to acquire positive health behaviors during adolescence period so that individuals can demonstrate healthy behaviors in the future. Participating students' HLSB was at moderate level. 